\title{
Triggering safer general practice care
}

\section{Susan M Dovey, Sharon Leitch}

Department of General Practice and Rural Health, University of Otago, Dunedin, New Zealand

\section{Correspondence to} Professor Susan M Dovey, Department of General Practice and Rural Health, University of Otago, 55 Hanover Street, Dunedin 9016, New Zealand; Susan.dovey@otago.ac.nz

Accepted 12 July 2016 Published Online First 2 August 2016

\section{Sinked}

- http://dx.doi.org/10.1136/ bmjqs-2015-004093

CrossMark

To cite: Dovey SM, Leitch S. BMJ Qual Saf 2017;26:259260.
We know for sure that healthcare does good things for a lot of people and that for some, it harms-sometimes concurrently with providing benefits. Quite likely doctors have known this for millennia, inspiring the caution in the Hippocratic oath to 'first do no harm'. Clinically grounded medical researchers know that medicine is complicated and that things can sometimes go wrong despite the best efforts of conscientious and well-intentioned clinicians. To minimise people's exposure to healthcare that harms them, while maximising their exposure to healthcare that helps, a diverse armamentarium has developed that includes tools such as alarms and alerts built in to equipment, postmarketing medicines surveillance, incident reporting systems, check lists, fish plots, run charts and many other things.

Concern over healthcare safety became increasingly widespread in the closing years of the 20th century but came relatively lately to primary care. Trigger tools are now part of the safety armoury of primary care clinicians. ${ }^{12}$ In this context, 'triggers' are a somewhat different safety tool from the physically engineered beeps and bells in equipment used by clinicians such as anaesthetists, although they serve a similar purpose-to warn of pending danger. To date in primary care, triggers have been used retrospectively to uncover otherwise undetected adverse events ${ }^{3}$ and assist in cancer diagnosis, ${ }^{4}$ and prospectively to alert clinicians to potential prescribing problems. ${ }^{5-8}$

In 2012, Sharek recommended the use of trigger tools as a superior strategy to adverse event reporting for measuring safety in healthcare. ${ }^{9}$ Trigger tools can be specific to particular functions such as prescribing or diagnosis, or they can be the more general 'global' trigger tools, such as the tool developed by the Institute for Healthcare Improvement ${ }^{10}$ and adapted for use in other countries.
There are three stages in trigger tool use. The first is to use the triggers to identify patients at high risk of experiencing a safety incident. The second is to review these patients' records to see if they did actually experience the effects of compromises in safety. The third stage, and the most critical if care is actually to be made safer for patients, is to learn from the previous two stages and implement some strategy to minimise patients' risk of future harm. The first stage, and perhaps a limiting factor to trigger tool use in many countries, is that high-risk patients can be most efficiently identified if their records are electronic and the searches are executed by computer programming.

However, to progress patient safety more is needed than for researchers and administrators to simply measure past events. Real learning must happen in the messy swamp of everyday clinical care so that the people providing care can see for themselves the consequences of their clinical decision making and decide for themselves what they might do differently. The challenge is to find out how to make the step change from research and administration to application in real life-at the micro or meso levels of individual providers and institutions, and also at the macro level of whole health systems. Where real life is the chaotic, idiosyncratic, uncontrolled and uncontrollable arena of primary care the challenge is profound.

The team from National Health Service Education for Scotland have stepped up to this challenge and developed a global trigger tool for use in general practice. ${ }^{1{ }^{11}}$ In this issue, de Wet et $a l^{12}$ demonstrate the successful widespread implementation of their global trigger tool by general practitioners (GPs), despite the challenges above. Voluntarily, but assisted by financial and contractual incentives, general practices in two Scottish regions were encouraged and trained to twice a year select and 
review 3 months of records from 25 patients their GPs considered 'high risk'. Most (86.2\%) practices agreed to do this. Eight selected triggers (defined as 'prompts' to indicate possible safety incidents) identified 1887 patient safety incidents that then generated 2175 actions to improve general practice care one way or another. This research is very important because for the first time it shows that a primary care patient safety measurement can be implemented across a health system and that it can prompt GPs to recognise opportunities to improve the care they provide and to make changes. All three stages of trigger tool use are applied in this report. If they can do it in Scotland they can do it in other places too.

Recently, frustration has started to be expressed with the lack of obvious efficacy of some strategies introduced with hopeful anticipation of solving modern healthcare's safety challenges. ${ }^{13}{ }^{14}$ Perhaps, trigger tools will follow the same path. This research, with its clinical engagement and ownership of solutions, suggests that maybe trigger tool application following the Scottish model is not just about measurement but is something new, important, different and potentially effective in actually improving healthcare safety.

Contributors SMD and SL wrote this editorial commentary together.

Competing interests None declared.

Provenance and peer review Commissioned; internally peer reviewed.

\section{REFERENCES}

1 De Wet C, Bowie P. The preliminary development and testing of a global trigger tool to detect error and patient harm in primary-care records. Postgrad Med J 2009;85:176-80.

2 Eggleton K, Dovey S. Using triggers in primary care records to flag increased adverse event risk and measure patient safety at clinic level. NZ Med J 2014;127:45-52.

3 Sarkar U, Handley M, Gupta R, et al. Use of an interactive, telephone-based self-management support program to identify adverse events among ambulatory diabetes patients. J Gen Int Med 2008;23:459-65.

4 Murphy D, Laxmisan A, Reis B. Electronic health record-based triggers to detect potential delays in cancer diagnosis. BMJ Qual Saf 2014;23:8-16.

5 Hume A, Quilliam B, Goldman R, et al. Alternatives to potentially inappropriate medications for use in e-prescribing software: triggers and treatment algorithms. BMJ Qual Saf 2011;20:875-84.

6 Joosten H, Drion I, Boogerd KJ, et al. Optimising drug prescribing and dispensing in subjects at risk for drug errors due to renal impairment: improving drug safety in primary healthcare by low eGFR alerts. BMJ Open 2013;3:e002068.

7 Singh R, Anderson D, McLean-Plunkett E, et al. IT-Enabled Systems Engineering Approach to Monitoring and Reducing ADEs. Am J Manag Care 2012;18:169-75.

8 Tamblyn R, Huang A, Taylor L, et al. A randomized trial of the effectiveness of on-demand versus computer-triggered drug decision support in primary care. J Am Med Inform Assoc 2008; $15: 430-8$.

9 Sharek P. Perspectives on Safety: The emergence of the trigger tool as the premier measurement strategy for patient safety. 2012. https://psnet.ahrq.gov/perspectives/perspective/120/theemergence-of-the-trigger-tool-as-the-premier-measurementstrategy-for-patient-safety [27 July 2016]

10 Naessens J, O’Byrne T, Johnson M, et al. Measuring hospital adverse events: assessing inter-rater reliability and trigger performance of the Global Trigger Tool. Int J Qual Health Care 2010;22:266-74.

11 McKay J, de Wet C, Kelly M, et al. Applying the Trigger Review Method after a brief educational intervention: Potential for teaching and improving safety in GP specialty training? BMC Med Educ 2013;13:117.

12 de Wet C, Black C, Luty S, et al. Implementation of the trigger review method in Scottish general practices: patient safety outcomes and potential for quality improvement. BMJ Qual Saf 2017;26:335-42.

13 Catchpole K, Russ S. The problem with checklists. BMJ Qual Saf 2015;24:545-9.

14 Mitchell I, Schuster A, Smith K, et al. Patient safety incident reporting: a qualitative study of thoughts and perceptions of experts 15 years after 'To Err is Human'. BMJ Qual Saf 2016;25:92-9. 